Pesq. Vet. Bras. 29(4):358-362, abril 2009

\title{
Estudo anatômico das artérias coronárias em caprinos ${ }^{1}$
}

\author{
Paulo César Moura Junior ${ }^{2}$, Tiago Henrique Marçal Vieira², Saulo Rodrigues \\ Coceira Vieira², João Leão Pinto Neto², Carlos Eduardo Silva Leão², \\ Adalgizzia Kelly Mello e Silva Lopes², Cristiane Regina Ruiz ${ }^{3 *}$, Gabriela \\ Cavallini Wafae ${ }^{4}$, Nailton Cavalcante da Silva ${ }^{6}$ e Nader Wafae ${ }^{5}$
}

\begin{abstract}
Moura Junior P.C., Vieira T.H.M., Vieira S.R.C., Leão J.P.N., Leão C.E.S.,Lopes A.K.M.S., Ruiz C.R., Wafae G.C., Silva N.C. \& Wafae N. 2009. [Anatomic study of coronary arteries in goats.] Estudo anatômico das artérias coronárias em caprinos. Pesquisa Veterinária Brasileira 29(4):358-362. Laboratório de Anatomia da União Educacional do Planalto Central (Uniplac), SIGA, Área especial no 2 Setor Leste Gama, Brasília, DF 72460-000, Brazil. E-mail: crisruiz@scamilo.edu.br

The coronary arteries of the goats have been used to researches about to pharmacological actions, heart failure after connection of coronary arteries and others. Twenty-seven goat hearts, both sexes, fixed in formalin at $10 \%$ has been used in this study that analyzed the coronary arteries pattern in goats and if the same is similar to the human coronary arteries pattern. The left coronary artery is dominant and in relation to the length demonstrated average $1.15 \mathrm{~cm}$ emitting two branches: interventricular paraconalis and circumflex. The interventricular paraconalis branch with average length $10.5 \mathrm{~cm}$ issued branches to the both ventricles fairly, ending more frequently in the interventricular subsinuosis sulcus. The circumflex branch with average length $8.5 \mathrm{~cm}$ issued branches to left ventricle and right atrium fairly. The left marginal branch is not constant. The right coronary artery, with average length $6.1 \mathrm{~cm}$ issued branches to right ventricle and right atrium fairly, but the interventricular subsinuosis branch with average length $3.1 \mathrm{~cm}$ is variable and can present one long branch, one short branch or one double branch, with the huge part for the right ventricle.
\end{abstract}

INDEX TERMS: Coronary dominance, interventricular paraconalis branch, interventricular subsinuosis branch.

RESUMO.- A utilização de artérias coronárias de caprinos em pesquisas experimentais com objetivos de futuras aplicações em coronárias humanas motivou o interesse em verificar semelhanças ou diferenças morfológicas das artérias coronárias de caprinos com os citados

\footnotetext{
${ }^{1}$ Recebido em 20 de agosto de 2008.

Aceito para publicação em 11 de março de 2009.

2 Graduando da União Educacional do Planalto Central (Uniplac), SIGA, Área especial № 2, Setor Leste Gama, Brasília, DF 72460-000, Brasil.

${ }^{3}$ Disciplina de Anatomia Humana, Centro Universitário São Camilo, Av. Nazareth 1501, São Paulo, SP 04263-200, Brasil. "Autor para correspondência: crisruiz@scamilo.edu.br

${ }^{4}$ Graduanda da Universidade Nove de Julho (Uninove), Rua Vergueiro 235, São Paulo, SP 01504-001.

${ }^{5}$ Disciplina de Anatomia Humana, Uniplac, Brasília, DF 72460-000, e Centro Universitário São Camilo, São Paulo, SP 04263-200.

${ }^{6}$ Laboratório de Anatomia da Uniplac, Brasília, DF 72460-000.
}

na literatura para humanos. Foram utilizados 31 corações de caprinos SRD pesando de 76,5-107,7g fixados em formalina a $10 \%$. As artérias coronárias e seus ramos eram dissecados até as ramificações visíveis sob o pericárdio. A artéria coronária esquerda presente em todos os corações era única. Seu comprimento situou-se entre $8 \mathrm{~mm}$ e $17 \mathrm{~mm}$, terminava formando os ramos: interventricular paraconal e circunflexo $(90,3 \%)$ ou interventricular paraconal, circunflexo e angular (9,7\%). O ramo interventricular paraconal, presente em todos os corações era único. Seu comprimento variou de 80 a $140 \mathrm{~mm}$, emitia média de 12 ramos. O ventrículo direito recebia $49,5 \%$ dos ramos e o ventrículo esquerdo, $50,5 \%$, dos ramos. Essa artéria podia terminar antes de atingir o ápice do coração $(22,5 \%)$, no próprio ápice $(22,5 \%)$ ou então passava pelo ápice e terminava no sulco interventricular subsinuoso (55\%). O ramo circunflexo era único, comprimento variou de 61 a 106mm, emitia média de 8,2 ramos. 
O ventrículo esquerdo recebia $53,4 \%$ dos ramos e o átrio esquerdo, $46,6 \%$. Em todos os casos essa artéria chegava e ultrapassava a Crux cordis. A artéria coronária direita, presente em todos os corações, era única. Seu comprimento variou de 35 a $86 \mathrm{~mm}$, emitia a média de 8,6 ramos. O ventrículo direito recebia $56,1 \%$, dos ramos e o átrio direito $43,9 \%$. Em geral era a própria artéria que se comportava como ramo marginal direito. A artéria coronária direita não atingia a Crux cordis em 93,5\%. O ramo interventricular subsinuoso da artéria circunflexa podia ser: a) ramo longo ocupando a maior parte do sulco; b) ramo curto ocupando apenas a parte superior do sulco; c) dois ramos ocupando o sulco. O comprimento variou de 5 a $51 \mathrm{~mm}$, emitia a média de 4,5 ramos sendo $63,2 \%$ para o ventrículo direito e $36,8 \%$ para o ventrículo esquerdo. Essa artéria podia terminar antes de atingir 0 ápice $(67,7 \%)$ ou no próprio ápice (32,3\%). Um de seus ramos ultrapassava a Crux cordis em $72 \%$ das peças.

TERMOS DE INDEXAÇÃO: Dominância coronária, ramo interventricular paraconal, ramo interventricular subsinuoso.

\section{INTRODUÇÃO}

Tem se verificado nos últimos anos, o aumento de pesquisas em corações de animais com o objetivo de observar suas aplicações na farmacologia experimental, na clínica e na cirurgia de corações humanos. Entre os animais, as coronárias de caprinos têm sido citadas na literatura com os seguintes objetivos: hiperemia reativa na circulação coronária (Fernandez et al. 2006, Climent et al. 2006), ações de fármacos em coronárias (Fernandez et al. 2005, Dieguez et al. 2004), vasodilatação coronária induzida (Deka et al. 2005), insuficiência cardíaca após ligadura da artéria coronária (Kim et al. 2003), modelos experimentais de infarto agudo do miocárdio (Shirakawa et al. 2005).

Apesar das inúmeras pesquisas que utilizam artérias coronárias de caprinos, as referências encontradas na literatura sobre estudos pomenorizados da anatomia dessas artérias são escassas. Tendo em vista que o conhecimento anatômico das artérias coronárias de caprinos poderá auxiliar a realização dessas pesquisas (Lipovetsky et al. 1983) inclusive, analisando se o padrão arterial de caprinos se assemelha ao padrão de coronárias humanas, para as quais várias dessas pesquisas se aplicam, propô-se realizar um estudo das artérias coronárias desta espécie.

\section{MATERIAL E MÉTODOS}

O material utilizado consistiu de 31 corações de caprinos sem raça definida, de ambos os sexos, pesando de 76,5-107,7g fixados e conservados em formalina a 10\%. Após a retirada do coração do interior do tórax do animal procedeu-se à lavagem da peça em água corrente para a retirada dos coágulos das cavidades e do interior das artérias coronárias. As artérias coronárias eram identificadas, e em algumas peças, para melhor exposição das artérias e de seus ramos, injetou-se através de uma cânula plástica a partir da aorta, Neoprene látex na cor vermelha. Em seguida, realizou-se à dissecação das artérias até as terminações macroscopicamente visíveis dos seus ramos, profundamente ao pericárdio.

A morfometria foi realizada utilizando-se um fio metálico estendido ao longo das artérias e de seus ramos, para em seguida, ser transferido a um paquímetro universal mecânico Digimess no 703032 no qual eram realizadas as medições. O ponto de referência denominado Crux cordis, adotado nesta pesquisa, corresponde ao cruzamento dos sulcos: coronário, interventricular subsinuoso e interatrial.

\section{RESULTADOS}

\section{Artéria coronária esquerda}

A artéria coronária esquerda presente em todos os corações era única (100,0\%). Seu comprimento situou-se entre 8 e $17 \mathrm{~mm}$, sendo $112 \mathrm{~mm}$ e $10-13 \mathrm{~mm}$ os valores mais freqüentes $(64,5 \%)$. Terminava formando os ramos: interventricular paraconal e circunflexo $(90,3 \%)$ ou interventricular paraconal, circunflexo e angular $(9,7 \%)$

Ramo interventricular paraconal. O ramo interventricular paraconal situado no sulco do mesmo nome, presente em todos os corações era único (100,0\%). Seu comprimento variou de 80 a $140 \mathrm{~mm}$, sendo $105 \mathrm{~mm}$ a média, emitia de 7 a 21 ramos, média de 12 ramos.

Desses ramos o ventrículo direito recebia $49,5 \%$, de 3 a 11 ramos, média 6,3 ramos e o ventrículo esquerdo recebia $50,5 \%$, de 3 a 10 ramos, média de 6,4 ramos. Essa artéria podia terminar antes de atingir o ápice do coração $(22,5 \%)$, no próprio ápice $(22,5 \%)$ ou então passava pelo ápice e terminava no sulco interventricular subsinuoso (55\%), sendo $34,3 \%$ no terço médio $20,7 \%$ no terço inferior (Fig. 1).

Ramo circunflexo. O ramo circunflexo, situado no sulco coronário, esteve presente em todos os corações e era único $(100,0) \%)$. Seu comprimento variou de 61 a $106 \mathrm{~mm}$, sendo 82 a média, emitia de 4 a 12 ramos, média de 8,2 ramos. Desses ramos o ventrículo esquerdo recebia $53,4 \%$, de 2 a 8 ramos, média de 4,5 ramos e o átrio esquerdo recebia $46,6 \%$, de 3 a 7 ramos, média de 3,9

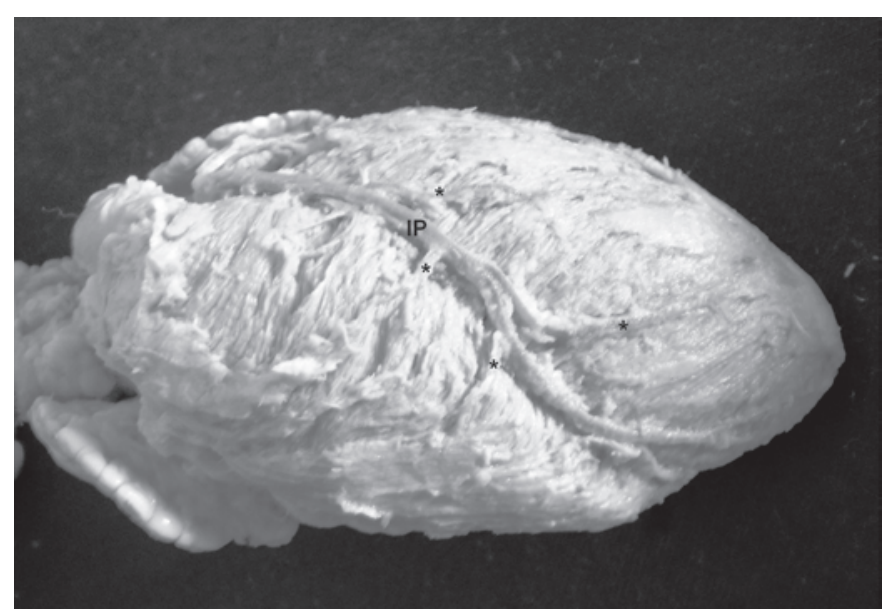

Fig.1. Ramo interventricular paraconal (IP) enviando ramos (*) para o ventrículo direito e para o ventriculo esquerdo e terminando no ápice. 


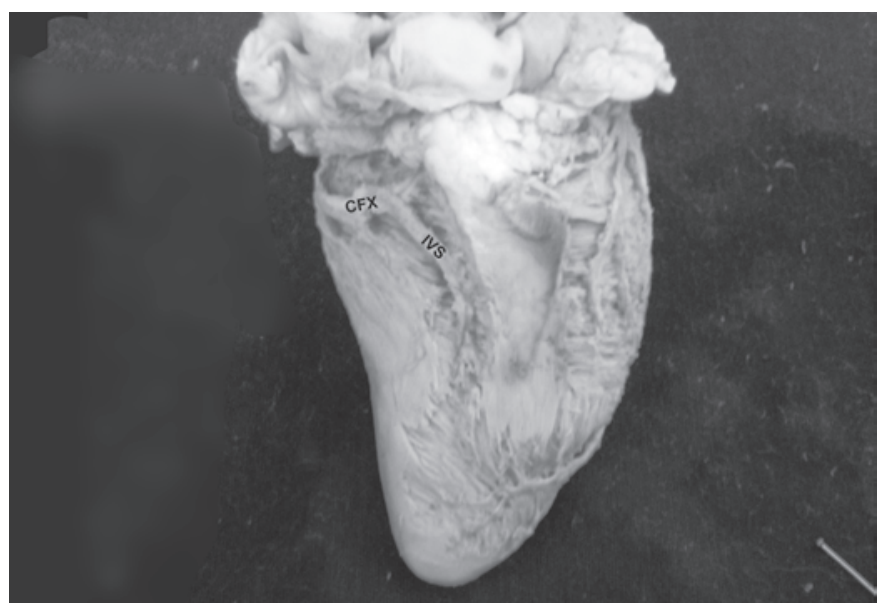

Fig.2. Ramo circunflexo (CFX) da artéria coronária esquerda emitindo o ramo interventricular subsinuoso longo (IVS).

ramos.

Em todos os casos essa artéria chegava até a Crux cordis $(100,0 \%)$, ultrapassando-a através de um ramo menor $(81,5 \%)$ ou um ramo maior $(18,5 \%)$. O ramo marginal do ventrículo esquerdo, com suas características anatômicas, só foi encontrado em 11 casos (35,5\%) embora outros pequenos ramos do ramo circunflexo se dirijam para a face esquerda, podia terminar antes de atingir o ápice (54,5\%) ou no próprio ápice (45,5\%) (Fig.2). Termina penetrando no sulco interventricular subsinuoso.

Artéria coronária direita. A artéria coronária direita, situada no sulco coronário, esteve presente em todos os corações, e era única (100,0\%). Seu comprimento variou de 35 a $86 \mathrm{~mm}$, sendo $60 \mathrm{~mm}$ a média e 6 a $6,8 \mathrm{~mm}$ os valores mais freqüentes $(48,1 \%)$, emitia de 5 a 16 ramos, média 8,6 ramos. Desses ramos o ventrículo direito recebia $56,1 \%$, de 3 a 9 ramos, média 4,9 ramos e o átrio direito recebia $43,9 \%$, de 2 a 7 ramos, média de 3,8 ramos. Embora essa artéria emita vários ramos para a região da margem direita, não se observou o ramo marginal direito com as características próprias de localização e extensão. Em geral, era a própria artéria coronária direita

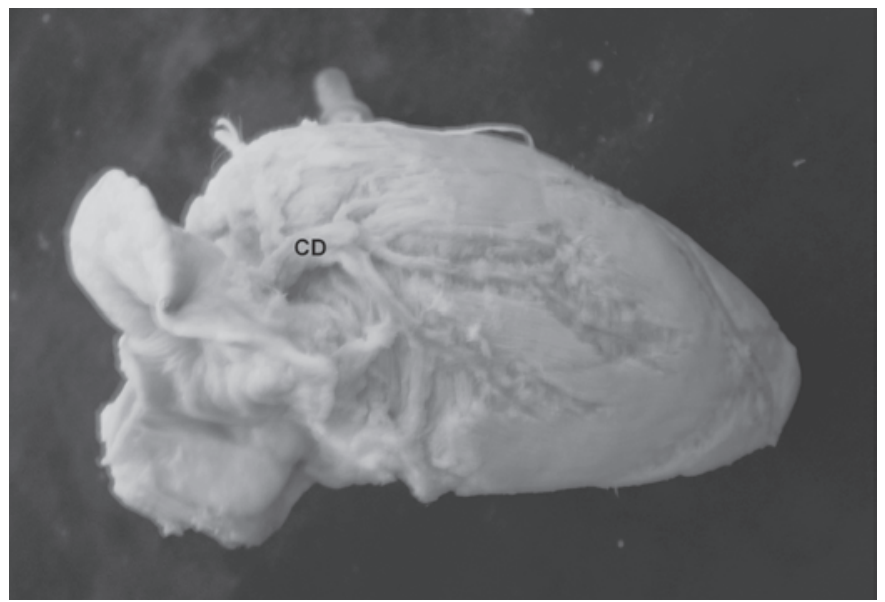

Fig.3. Artéria coronária direita (CD). que se comportava como marginal. A artéria coronária direita não atingia a Crux cordis em 93,5\% dos casos e mesmo nos dois casos (6,5\%) em que chegou a Crux cordis, sua participação na formação do ramo interventricular posterior era muito pequena (Fig.3).

Ramo interventricular subsinuoso. Terminação do ramo circunflexo pode apresentar as seguintes disposições:

a) ramo longo ocupando a maior parte do sulco interventricular subsinuoso em 15 casos ou $48,4 \%$.

b) ramo curto ocupando apenas a parte superior do sulco interventricular subsinuoso a parte inferior era ocupada pelo ramo interventricular paraconal em 10 peças $32,3 \%$.

c) dois ramos emitidos pelo ramo circunflexo, ambos ocupando o sulco interventricular subsinuoso, o superior emitido no nível da Crux cordis e o inferior emitido pouco antes da Crux cordis 6 casos ou 19,3\%.

O comprimento variou de 5 a $51 \mathrm{~mm}$, média $31 \mathrm{~mm}$, emitia de 1 a 8 ramos, média 4,5. Desses ramos 63,2\% para 0 ventrículo direito e $36,8 \%$ para o ventrículo esquerdo. Esse ramo podia terminar antes de atingir o ápice $(67,7 \%$ ) ou no próprio ápice (32,3\%). Pelo menos, um de seus ramos ultrapassava a Crux cordis em $72 \%$ das peças (Fig.4).

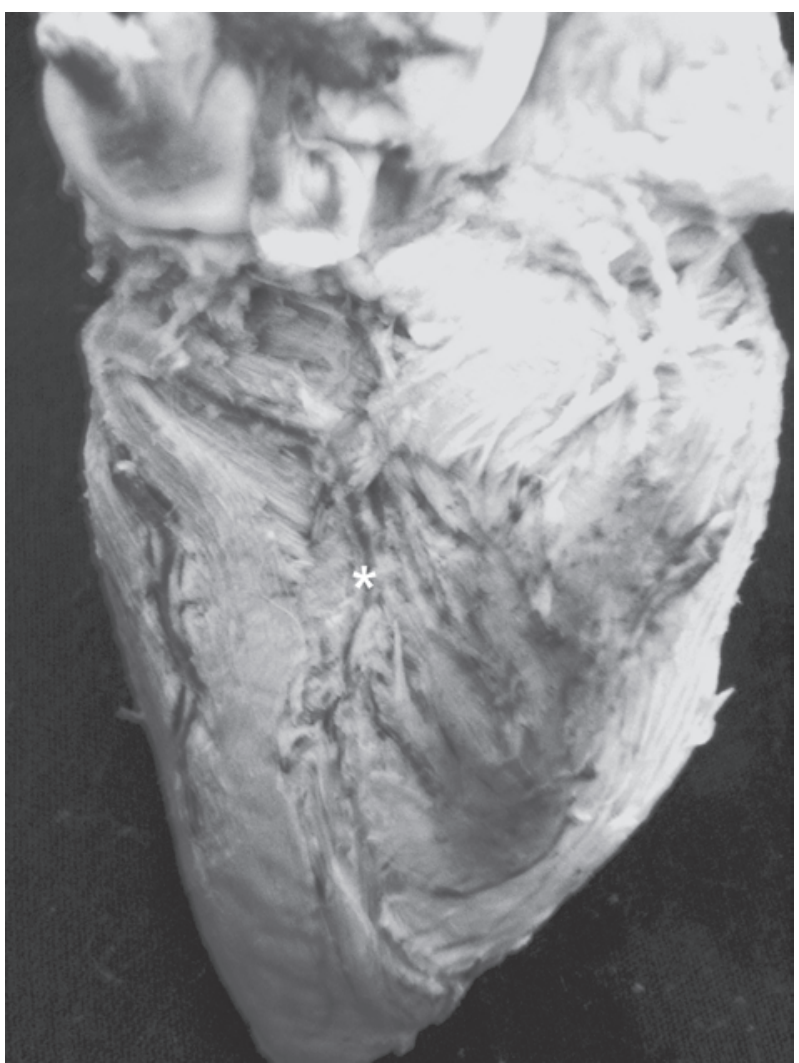

Fig.4. Ramo interventricular subsinuoso longo (*).

\section{DISCUSSÃO}

Como as artérias coronárias de caprinos têm sido utilizadas em pesquisas experimentais (Kim et al. 2003, Dieguez et al. 2004, Fernandez et al. 2005, 2006, Shirakawa et al. 
2005, Deka et al. 2005, Climent et al. 2006), para aplicação futura em corações humanos, achou-se oportuno verificar a existência de semelhanças na distribuição das artérias coronárias entre caprinos e humanos. A artéria diagonal esteve presente em $9,7 \%$ das peças de caprinos, já em corações humanos a freqüência é de $45,3 \%$ (Baptista et al. 1991).

Nos caprinos, o ramo interventricular paraconal emite, equitativamente, ramos para ambos os ventrículos e atinge o ápice em 77,5\%. Para Baptista (1986) e Baptista et al. (1988), os ramos são distribuídos na proporção de $25 \%$ para o ventrículo direito e $75 \%$ para o ventrículo esquerdo e atinge o ápice em $95 \%$ dos corações humanos.

Mas a principal diferença encontra-se no ramo circunflexo que nos humanos termina em $86,1 \%$ dos casos antes da Crux cordis e forma o ramo interventricular posterior (subsinuoso) apenas em $10 \%$ dos casos (Baptista et al. 1990). Esta pesquisa demonstrou que nos caprinos, o ramo circunflexo sempre atinge a Crux cordis $(100,0 \%)$, ultrapassa esse ponto através de seus ramos e forma 0 ramo interventricular subsinuoso.

A artéria coronária direita que nos corações humanos é longa forma o ramo interventricular posterior (subsinuoso) e ultrapassa a Crux cordis em $88,8 \%$ (Baptista et al. 1989), nos corações de caprinos é curta, raramente atinge a Crux cordis e sua participação no sulco interventricular subsinuoso é muito pequena $(6,5 \%)$.

Assim, a utilização das artérias coronárias de caprinos em projetos experimentais com o objetivo de aplicação futura em coronárias humanas deve considerar que os padrões de distribuição arterial são diferentes e avaliar se a generalização pode ser realizada.

Comparando os resultados deste trabalho com os resultados obtidos por Lipovetsky et al. 1983, verificou-se que esses autores encontraram a artéria diagonal apenas em $1 \%$ das peças, a artéria coronária esquerda esteve ausente em 3\% (nessas peças os ramos interventricular paraconal e circunflexo emergiam diretamente da aorta), o ramo paraconal passava para o sulco interventricular subsinuoso em $94 \%$, emitia com maior freqüência (76\%) de 3 a 5 ramos para o ventrículo esquerdo e o ramo marginal do ventrículo esquerdo, sempre presente, chegava ao ápice em $34 \%$ das peças. Nesta pesquisa: a artéria coronária esquerda sempre esteve presente, a artéria diagonal foi observada em $9,7 \%$, o ramo interventricular paraconal passava para o sulco interventricular subsinuoso em $77,5 \%$, o ventrículo esquerdo recebia com maior freqüência (80\%) de 4 a 7 ramos e o ramo marginal do ventrículo esquerdo presente em $35,5 \%$ chegava ao ápice em 45,5\%. Para Lipovetsky et al. 1983, o ramo interventricular subsinuoso ocupava os terços: superior e médio em $66 \%$, chegava ao ápice em $34 \%$, era um ramo em $80 \%$ e dois ramos em $12 \%$. Em nossa pesquisa: 0 mesmo ramo ocupava os terços: superior e médio em $48,4 \%$, chegava ao ápice em $32,3 \%$ e apresentava um ramo em $80 \%$ e dois ramos em $19,3 \%$. Em relação à artéria coronária direita, ambas as pesquisas foram concordantes quanto à extensão e emissão de ramos.

\section{CONCLUSÕES}

O coração de caprinos apresenta duas artérias coronárias: direita e esquerda que se originam nos seios da aorta correspondentes.

A artéria coronária esquerda é curta e termina em dois ramos: interventricular paraconal e circunflexo, mas em baixa freqüência pode emitir também o ramo diagonal.

O ramo interventricular paraconal é o mais longo, emite número semelhante de ramos para ambos os ventrículos e termina, mais freqüentemente no sulco interventricular subsinuoso.

O ramo circunflexo é longo, emite ramos para o ventrículo e átrio esquerdos, termina na Crux cordis e seus ramos atravessam esse ponto. O ramo marginal do ventrículo esquerdo é inconstante e quando presente termina antes do ápice.

A artéria coronária direita é curta, emite ramos para o ventrículo direito e átrio direito em número semelhante e termina antes da Crux cordis.

O ramo interventricular subsinuoso, terminação do ramo circunflexo da artéria coronária esquerda é variável em sua disposição, pode se apresentar como ramo longo ocupando a maior parte do sulco ou ramo curto ocupando apenas parte superior do sulco ou como ramo duplo. A maioria de seus ramos destina-se ao ventrículo direito, em geral termina antes do ápice e pelo menos um de seus ramos ultrapassa a Crux cordis.

A artéria coronária esquerda é dominante conseqüentemente o padrão arterial de caprinos é diferente do padrão arterial humano.

\section{REFERÊNCIAS}

Baptista C.A.C.S. 1986. Distribuição dos ramos das artérias coronárias na superfície ventricular do coração humano. Dissertação de mestrado, Escola Paulista de Medicina, Universidade Federal de São Paulo (Unifesp), São Paulo. 193p.

Baptista C.A., DiDio L.J., Davis J.T. \& Teofilovski-Parapid G. 1988.The cardiac apex and its superficial blood supply. Surg. Radiol. Anat. 10(2):151-160.

Baptista C.A., DiDio L.J. \& Teofilovski-Parapid G. 1989. Variation in length and termination of the right coronary artery in man. Jpn. Heart J. 30(6):789-798.

Baptista C.A., DiDio L.J. \& Teofilovski-Parapid G. 1990. Variation in length and termination of the ramus circunflexus of the human left coronary artery. Anat. Anz. 171(4):247-253.

Baptista C.A., DiDio L.J. \& Prates J.C. 1991. Types of division of the left coronary artery and the ramus diagonalis of the human heart. Jpn. Heart J. 32(3):323-335.

Climent B., Fernandez N., Sanchez A., Garcia-Villalon A.L., Monge L. \& Dieguez G. 2006. Vasoconstrictor prostanoids may be involved in reduced coronary reactive hyperaemia after ischemia-reperfusion in anesthetized goats. Eur. J. Pharmacol. 530(3):234-242.

Deka D.K., Ravi Prakash V. \& Mishra S.K. 2005. Sodium nitroprusside relaxes goat coronary artery through activation of calcium-dependent K + channels. Indian J. Exp. Biol. 43(4):324-329.

Dieguez G., Martinez M.A., Fernandez N., Climent B., Garcia-Villalon A.L. \& Monge L. 2004. Vasopressin effects on the coronary circulation after a short ischemia in anesthetized goats: Role of nitric oxide and prostanoids. Eur. J. Pharmacol. 495(2/3):171-177. 
Fernandez N., Monge L., Garcia-Villalon A.L. \& Dieguez G. 2006. Coronary reactive hyperaemia and arterial pressure in anesthetized goats. Exp. Physiol. 91(5):915-923.

Fernandez N., Martinez M.A., Garcia-Villalon A.L., Monge L. \& Dieguez G. 2005. Coronary effects of endothelin-1 and vasopressin during acute hypotension in anesthetized goats. Life Sci. 77 (4):423-434.

Kim W.G., Cho S.R., Sung S.H. \& Park H.J. 2003. A chronic heart failure model by coronary artery ligation in the goat. Int. J. Artif. Organs 26(10):929-934.
Lipovetsky G., Fenoglio J.J., Gieger M., Srinivasan M.R. \& Dobelle W.H. 1983. Coronary artery anatomy of the goat. Artif. Organs 7(2):238245.

Shirakawa Y., Sawa Y., Takewa Y., Tatsumi E., Kaneda Y., Taenaka Y. \& Matsuda H. 2005. Gene transfection with human hepatocyte growth factor complementary DNA plasmids attenuates cardiac remodeling after acute myocardial infarction in goat hearts implanted with ventricular assist devices. J. Thorac. Cardiovasc. Surg. 130(3):624632. 